Culture et histoire dans l'espace roman

$6 \mid 2011$

Figures du pouvoir dans la littérature hispanoaméricaine

\title{
Figuras del poder en la sociedad cubana retratada por Leonardo Padura
}

\section{Paula Martinez}

\section{(2) OpenEdition}

\section{Journals}

Edición electrónica

URL: https://journals.openedition.org/cher/9392

DOI: $10.4000 /$ cher.9392

ISSN: 2803-5992

\section{Editor}

Presses universitaires de Strasbourg

\section{Edición impresa}

Fecha de publicación: 30 junio 2011

Paginación: 247-256

ISBN: 978-2-35410-033-9

ISSN: 1968-035X

\section{Referencia electrónica}

Paula Martinez, «Figuras del poder en la sociedad cubana retratada por Leonardo Padura»,

reCHERches [En línea], 6 | 2011, Publicado el 17 diciembre 2021, consultado el 24 enero 2022. URL: http://journals.openedition.org/cher/9392 ; DOI: https://doi.org/10.4000/cher.9392

\section{(c) (†) (-)}

Ce(tte) œuvre est mise à disposition selon les termes de la Licence Creative Commons Attribution -

Pas d'Utilisation Commerciale - Partage dans les Mêmes Conditions 4.0 International. 


\title{
Figuras del poder en la sociedad cubana retratada por Leonardo Padura
}

\author{
PaULa MARTINEZ \\ Université François Rabelais - Tours
}

$\mathrm{T}$ anto en sus novelas como en su obra periodística Leonardo Padura describe como pocos la sociedad cubana actual. Una sociedad repleta de contrastes y contradicciones, en la que la vida cotidiana está marcada por las dificultades para sobrevivir.

En la Cuba inmediatamente posrevolucionaria el gobierno ejercía un poder de control muy fuerte sobre el pueblo. Es un poder que podríamos calificar de "omnipresente" durante los primeros veinte o treinta años después de la Revolución y que, sin embargo, después de la crisis de finales de los ochenta aparece debilitado y sustituido, en parte, por otras formas de poder. El creciente individualismo y la pérdida de valores culturales y sociales han transformado de forma vertiginosa la vida de los cubanos de forma que descubren (o vuelven a descubrir) la violencia urbana, el atractivo del dinero y de la acumulación de riquezas, así como el refugio de lo religioso en tiempos de crisis. Lo material y lo religioso reemplazan a los ideales revolucionarios.

Nos proponemos reflexionar en estas páginas sobre las representaciones concretas de los diferentes "poderes" en las novelas escritas por Leonardo Padura. Por una parte, ¿qué visión nos da de la Revolución con el paso de los años? ¿Cuáles son las relaciones que establecen con el poder político los diferentes personajes que aparecen de forma recurrente en su obra?, por otra parte, ¿qué retrato nos brinda Padura de la sociedad cubana? 


\section{Leonardo Padura : un escritor crítico y popular}

Leonardo Padura Fuentes nace en La Habana en 1955. Obtiene una licenciatura en Filología por la Universidad de La Habana, en 1980. Es narrador, periodista, guionista de cine, crítico y ensayista. Como periodista ha trabajado en la revista El Caimán Barbudo (1980-1983), el periódico Juventud Rebelde (1983-1989), y ha sido Jefe de Redacción de la revista cultural La Gaceta de Cuba (1989-1995).

Sus obras más conocidas son las que ponen en escena a Mario Conde (y son precisamente estas obras las que van a centrar nuestra atención), policía en la tetralogía de las cuatro estaciones: Pasado perfecto (1989), Vientos de cuaresma (1994), Máscaras (1997) y Paisaje de otoño (1998) y librero de viejo en Adiós, Hemingway (2001) y La neblina del ayer (2005). Ha escrito también La novela de mi vida (2002) sobre el poeta José María Heredia y El hombre que amaba a los perros (2009) sobre el asesinato de Trotski.

Ha sido galardonado en numerosas ocasiones tanto en Cuba, donde recibe varios Premios de la Crítica y el Premio Nacional de Novela en 1993, como en el extranjero, con el Café Gijón en 1995, el premio Hammett en 1997, 1998 y 2005, el Premio de las Islas 2000 o el Brigada 21 a la mejor novela del año. Es, sin duda, un escritor con éxito dentro y fuera de su país.

Nacido, como decíamos, en 1955, Padura ha vivido casi toda su infancia y toda su vida adulta con la Revolución, en cuyos principios fue educado, tal como lo explica en 2004 a Doris Wieser:

Yo en el año 1959 tenía cuatro años. Es decir que yo hago toda mi vida adulta en el proceso revolucionario, empiezo a estudiar, a ir a la escuela cuando ya ha triunfado la Revolución. Crecimos dentro del proceso y fuimos parte del proceso porque como estudiantes primero y después cuando empezamos a trabajar en los años 80 éramos gente que participábamos directamente del proceso revolucionario. Nuestro concepto y nuestra manera de pensar fueron moldeados por la vida en la Cuba revolucionaria.

Educado en este contexto, forma parte de la generación que creyó con ilusión en la labor de la Revolución y para la cual el desencanto fue enorme cuando en los años 90 se desintegra la Unión Soviética y Cuba se queda sola.

Por eso, cuando a partir del año 89/90 esa realidad comienza a cambiar, no solamente en Cuba sino también en Europa y en la Unión Soviética, que llega a desintegrarse como estado, empezamos a ver la realidad de otra manera, empezamos a tener una visión más compleja, más profunda de lo que habían sido nuestros propios años y los años de la vida en Cuba que habían 
transcurrido hasta entonces [...]. Todo eso conmovió la manera de pensar de la gente en Cuba y de mi generación en particular (Wieser 2005).

No cabe duda de que, al menos a partir de este momento, y a pesar de que el autor mantiene una cierta ambigüedad con respecto a su posición política cuando los periodistas le preguntan lo que piensa del gobierno de su país, la visión que tiene Padura del poder político y de las altas esferas cubanas es muy crítica.

Estas opiniones críticas están muy presentes en toda su obra, ya sea en las novelas o en los artículos de opinión. El propio Padura explica que no existe un verdadero periodismo en Cuba que permita reflejar la sociedad actual, puesto que todos los periódicos pertenecen al Estado. El periodismo cubano hecho desde fuera de Cuba tiene a menudo tendencia a mostrar únicamente los puntos negativos, mientras que el realizado desde dentro sólo muestra los puntos positivos. Esto se refleja también en sus novelas, en las que habla de la prensa con mucha ironía:

Según las páginas internacionales del periódico el mundo parecía estar bastante jodido, aunque los países socialistas - a pesar de las dificultades y de incesantes presiones internas - estaban decididos a no abandonar la senda ascendente y victoriosa de la historia. Las páginas nacionales, por su parte, demostraban que la isla no estaba nada mal, salvo algún imprevisto, como el del accidente ferroviario que había dejado varios muertos ( $\mathrm{y}$ que por supuesto no estaba planificado) (Padura 1997: 153).

Padura piensa que, ante el vacío informativo dejado por la prensa, la novela en general, y más particularmente la novela policiaca, es la mejor forma de vehicular su visión de la realidad con el fin de provocar una reflexión sobre la Cuba actual. No hay que olvidar que, a pesar de que las ediciones que nosotros conocemos de las obras de Padura son españolas, todas sus novelas se publican en Cuba, donde es considerado como el más popular de los escritores contemporáneos. El autor dice sentirse más libre por el hecho de publicar sus libros en España, aunque mantiene que él escribe desde Cuba y para los cubanos.

\section{Novela policiaca, un modelo oficial}

Volviendo a la elección de Padura, podemos preguntarnos por qué escoge precisamente la novela policiaca, tan ligada históricamente al discurso oficial del Régimen. Es importante recordar que el género vive su periodo de auge cuando, después del Primer Congreso de Educación y 
Cultura celebrado en La Havana en abril de 1971 bajo el lema de «el arte es un arma de la Revolución", se crea el Premio Aniversario de la Revolución ${ }^{1}$ dedicado a la novela policiaca. Este congreso consolida un giro drástico en la política revolucionaria en lo que concierne a la cultura que, si bien fue durante la mayor parte de la década de los sesenta relativamente «permisiva hacia los más diversos experimentos estéticos y formales» (Padura 2010), se transforma al final de la misma en una "política cultural férrea, ortodoxa y en buena medida represiva contra todo lo que cayera [...] fuera de la revolución».

Todos los críticos admiten que se trata de una novela de escasa o nula calidad literaria, instrumento de ideologización del pueblo cubano. En la novela policiaca revolucionaria los detectives son siempre perfectos representantes del gobierno que luchan, con la ayuda del pueblo cubano, contra personajes contrarios a la revolución. Es algo así como la lucha del bien contra el mal, en la que, por supuesto, el bien gana siempre. El propio Padura la define como "una simplista y didactista literatura para niños y jóvenes, y un impulso silencioso pero perceptible de un cierto realismo socialista a la cubana» (Padura 2010).

Durante los años ochenta empiezan a percibirse signos de cambio, al menos parcial, en la literatura cubana, en la cual se empiezan a colocar los conflictos humanos por encima de los contenidos políticos. En los noventa, la desintegración del bloque socialista y la consiguiente crisis económica tuvieron como consecuencia carencias materiales y un perceptible desencanto político que provocaron una doble "revolución" literaria. Por una parte aparecen obras sobre los conflictos de la realidad vistos de forma crítica, en las que se tratan temas hasta entonces tabú en la literatura cubana, como la corrupción, la existencia de diferencias sociales, el racismo, la miseria, etc. Por otra se produce el divorcio entre la industria cultural cubana (privada de medios materiales para publicar) y los autores, que se ven obligados a buscar otros mercados.

\section{Inversión de roles : poder y corrupción}

Este es el contexto en el cual Leonardo Padura escribe y publica (inicialmente en México) su primera novela Pasado Perfecto. En ella recupera el género policiaco que utiliza como instrumento estético y político. Ya no se trata de una novela al servicio del poder sino de una novela crítica con el

1 Primera edición en 1971. 
mismo: Padura critica a las altas esferas invirtiendo los roles. Los criminales y las víctimas, al contrario de la novela policial anterior, son siempre altos cargos de la administración. El propio Padura lo explica así en la entrevista No sé vivir en otra parte:

Ese fue un propósito absolutamente meditado. Yo no quería que los delincuentes de mis novelas fueran un negro que entra por una ventana y se roba un jarrón o un delincuente callejero que le da una puñalada a otro en una pelea. Traté de mover el mundo del delito hacia otro sector de la sociedad. Es el sector de estos intachables, de estos perfectos que generalmente, cuando cometen un delito, lo cometen en unas proporciones mayores porque afectan a muchas personas. Mi intención desde el principio fue convertir estas novelas en una visión diferente de la realidad cubana a la que había dado la novela policíaca anterior. En la novela policíaca anterior los buenos y los malos estaban muy bien marcados. Los delincuentes eran malos, los policías eran buenos, los agentes del enemigo eran malos, los agentes del orden de la seguridad del estado eran buenos. Yo traté de subvertir todo eso (Padura 2010).

En su novela Pasado Perfecto, Rafael Morín, ex-compañero del Pre de Mario Conde y "cuadro de plena confianza» es en realidad un dirigente corrupto que se ha enriquecido robando en su trabajo y que es asesinado por su jefe de despacho, René Maciques, igualmente corrupto. Este caso es mostrado no como una excepción sino como algo generalizado, como podemos ver en este diálogo de Mario Conde con su jefe:

-Las barbaridades están de moda, Viejo... ¿ ¿No era un cuadro de plena confianza? ¿No era un hombre de futuro interminable? ¿No era más puro y más santo que el agua bendita?

-No te pongas sarcástico ahora, porque eso no explica nada...

-Viejo, no sé por qué te asombra que haya esa falta de control en una empresa. Cada vez que se hace una auditoría sorpresiva de verdad, donde quiera aparecen las barbaridades que nadie se puede imaginar, que nadie se explica, pero que están siempre ahí. Ya se te olvidó el administrador millonario de la Ward, el del Pío-Pío, y el de... (Padura 2000 : 197).

En Vientos de Cuaresma Lissette Núñez, una joven profesora del Preuniversitario de La Vívora, el mismo en el que Mario Conde estudió, aparece asesinada. La chica, que aparentemente es perfecta, resulta tener una vida sexual promiscua con el director del pre y con un alumno al que comunica las preguntas de los exámenes y que acaba matándola. Una vez más esta historia particular aparece como representativa de la corrupción reinante en la isla: 
Bonita historia, ¿no? -preguntó el Viejo y se puso de pie-. Un muchacho de pre y una profesora como protagonistas y un director, un mercader de motocicletas y un traficante de marihuana en los papeles secundarios; hay de todo, de todo: sexo, violencias, drogas, crímenes, alcohol, fraude, tráfico de divisas, favores sexuales bien retribuidos [...] da ganas de vomitar (211).

En Máscaras el alto funcionario Faustino Arayán mata a su hijo Alexis, por ser homosexual, y en Paisaje de otoño un ex-alto dirigente es asesinado cuando vuelve a Cuba desde Miami para recuperar un objeto valorado en varios millones de dólares del cual se había apropiado indebidamente en su época de dirigente. Y una vez más no es el único corrupto en las altas esferas ya que es significativa también en la novela la presencia de Gerardo Gómez de la Peña, hombre arrogante que presume de poseer un Matisse adquirido de forma poco ortodoxa y cuyo precio es superior a los tres millones de dólares. El encuentro entre Conde y este personaje sirve para que el policía descubra una realidad social que ignoraba: la de la gente que vive en los barrios ricos, que posee bellos objetos y que no soporta las mismas penurias que la mayoría de los cubanos.

La corrupción también toca a la policía, y es la causa de que Mario Conde la abandone definitivamente después de que ésta le costase la expulsión al Mayor Rángel. También en esta ocasión se habla de corrupción generalizada y no de un caso aislado:

el Conde sabía perfectamente de los miedos que había sufrido Manolo en los últimos meses de investigaciones, purgas y expulsiones, durante los cuales todos habían sido interrogados en varias ocasiones, para que saltaran las liebres más inesperadas: colegas de veinte años traicionándose enconadamente, viejos policías intachables descubiertos como malandrines consuetudinarios, casos sepultados bajo cantidades insospechadas de billetes, favores consentidos a cambio de las más disímiles mercancías: desde un sexo joven y abultado hasta un título universitario sin asistir a clases [...] (Padura 1998: 31).

Frente al discurso oficial que sigue hablando del orden social, de la purificación del individuo y del "hombre nuevo", la corrupción está presente en todos los niveles sociales, con la diferencia de que en el caso de las clases altas aparece como totalmente gratuita (provocada por el afán de poseer cada vez más) y en el caso de las clases populares es consecuencia directa de la miseria que sufre el pueblo cubano. Entre los amigos del pre de Mario Conde hay uno, Candito el Rojo, que vive de negocios ilegales. El policía no sólo no lo condena sino que transgrede la ley cuando lo avisa de que su negocio ha sido descubierto y de que debe desmantelarlo e irse. También 
Jose, la madre de Carlos el Flaco, adquiere víveres para sus suculentos festines en el mercado ilegal. Otros amigos, como Dulcita, y más tarde Andrés, aparecen como políticamente incorrectos por huir de la isla hacia Miami. Sin embargo, si bien el texto muestra la incomprensión y la tristeza de Conde y su amigo Carlos ante los que se van, también transmite el mucho cariño que sienten hacia ellos. El policía y su amigo no les reprochan su conducta, quizás porque piensan que Miami, y en concreto la Pequeña Habana, están lejos de ser un paraíso:

La calle 8 no es más que eso: una calle fabricada con la nostalgia de los de Miami y con los sueños de los que queremos ir a Miami. Es como las ruinas falsas de un país que no existe ni existió, y lo que queda de él está enfermo de agonía y prosperidad, de odio y de olvido. [...] Miami es nada. Porque lo tiene todo pero le falta lo más importante: le falta el corazón (75-76).

Otra de las críticas al poder establecido es relativa a la vigilancia de la policía interna. Tenemos la impresión de que todo el mundo es vigilado en Cuba en todo momento. Hasta los personajes que parecen simpáticos e inofensivos, como la secretaria Maruchi, pueden pertenecer a la policía interna. Manolo, el compañero de trabajo del Conde, describe bien la situación:

uno siente que está viviendo en una urna transparente, o en un tubo de ensayo, no sé, y que lo ven a uno cagar, mear y hasta sacarse los mocos, porque creo que saben si uno los hace bolitas para tirarlos o si los pega debajo de una mesa: eso sí me horrorizó: nos tienen retratados y saben todo lo que hacemos y lo que no hacemos y todo les interesa [...] de verdad que eso sí da miedo (Padura 1997: 127-128).

Padura critica igualmente la represión intelectual de los años setenta, a la que dedica su novela Máscaras, en que Alberto Marqués es trasunto de Virgilio Piñera, detenido por su homosexualidad en la noche de las tres $\mathrm{P}^{2}$ y aislado y censurado después. A pequeña escala el mismo Conde y sus compañeros del pre sufrieron la represión cuando las autoridades retiraron la revista literaria de su instituto porque al director no le parecía conforme con la Revolución. El pasaje que sigue muestra bien lo ridículo del acto:

El director $[\ldots]$ hizo abuso de la palabra: ¿Qué quería decir ese lema de la revista de que "El Comunismo será una aspirina del tamaño del sol", acaso

2 El Ministerio del Interior ordena redadas policiales contra las prostitutas, proxenetas y "pájaros»- como se llama a los gays en Cuba -, en lo que se denomina «la noche de las tres $\mathrm{P}$ ». Estas redadas se hacen también durante el día. Entre los muchos detenidos, figura el escritor Virgilio Piñera, quien duerme una noche en los calabozos de la prisión de El Príncipe. 
que el socialismo era un dolor de cabeza? [...] ¿Por qué todos, todos los poemas de la revista eran de amor y no había uno solo dedicado a la obra de la Revolución, a la vida de un mártir, a la patria en fin? ¿Por qué el cuento del compañerito Conde era de tema religioso y eludía una toma de partido en contra de la iglesia y su enseñanza escolástica y retrógrada? (Padura 2000: 59).

\section{El desencanto cada vez más presente.}

Es necesario señalar que, a lo largo de la obra de Padura, se produce une evolución en lo que concierne a la crítica de la represión intelectual, muy presente en Máscaras, y en general en toda la serie Las cuatro estaciones en las que se describe La Havana de 1989, pero ya menor en La neblina del ayer, ambientada en el año 2003. Al mismo tiempo y siempre en un afán de descripción de la evolución de la sociedad cubana, asistimos a una generalización del desorden social provocado por las dificultades económicas y el desencantamiento del Periodo Especial. Para Leonardo Padura, a medida que pasa el tiempo la sociedad cubana se sitúa cada más lejos de los ideales de la Revolución.

En La neblina del ayer Mario Conde (que ahora se dedica a comprar y vender libros antiguos) va a ver a su antiguo compañero Manolo (que sigue siendo policía) para pedirle un favor. Manolo le habla entonces de los cambios sociales:

Ahora se meten crack, cocaína, parkisonil con ron y anfetaminas, cuando pueden. Si no, cualquier pastilla para los nervios con alcohol y hasta anestesia de animales, oye tú [...]. Pero no vayas a creerte que son tres [...]. Mira, cada vez que hay un baile público o una pelea de perros, o cuando están aburridos, se meten lo que encuentran y después están que se matan entre ellos: pero se matan de verdad... Y sacan el dinero de cualquier parte, pero casi siempre lo consiguen robando, puteando o vendiendo drogas a los otros. O se les ocurre meterse en una casa, robarse cualquier cosa, y en el camino pueden dejar dos o tres muertos.

- Los periódicos no hablan de estas cosas... ¿Y alguien se pregunta por qué pasa eso? -quiso saber el Conde, alarmado ante el panorama dibujado por su ex compañero y congratulándose de estar lejos de aquella tétrica realidad en expansión (Padura 2005: 105-106).

Desde el punto de vista físico, las descripciones de La Havana también cambian, de forma que la degradación se hace cada vez más presente, como podemos ver a partir de esta descripción del barrio chino de La neblina del ayer: 
la zona seguía exhibiendo, casi descaradamente, un deterioro furioso, al parecer imparable, que emergía desde los hoyos callejeros, desbordados de aguas públicas, para trepar por los latones repletos de desperdicios hasta alcanzar la verticalidad de las paredes, carcomiéndolas y derribándolas en más de un caso. Aquellas viejas edificaciones de principios del siglo XX, muchas de ellas convertidas en solares donde se hacinaban varias familias, habían olvidado hacía demasiados años el posible encanto que alguna vez pudieron tener y en su decadencia irreversible ofrecían un panorama de compacta pobreza. Negros, blancos, chinos y mestizos de todas las sangres y creencias convivían allí con una miseria que no distinguía tonalidades epidérmicas y procedencias geográficas, igualándolos a todos, empujándolos a una lucha por la supervivencia que solía tornarlos agresivos y cínicos, como seres ya ajenos a cualquier esperanza (138).

Lejos del ideal revolucionario, Padura parece mostrarnos, a través de la decadencia física y moral, una sociedad sin rumbo, sin valores. A diferencia de lo que ocurría en los años sesenta o setenta en los que el poder político controlaba la sociedad, la realidad actual es muy diferente. Esta pérdida de poder real podría explicar el cambio de estrategia del gobierno, que permite críticas abiertas al Régimen hasta hace algunos años impensables. Esto explica que autores como el propio Padura, Wendy Guerra o Pedro Juan Gutiérrez, entre otros, puedan publicar sus obras en la isla.

Indiscutiblemente existe una mayor libertad de expresión en lo que concierne a la literatura, que ocupa, como decíamos, una parte del espacio que le correspondería a la prensa. Sin embargo la situación social del país descrita por Leonardo Padura es más que inquietante.

Acabaremos con una reflexión de Mario Conde ante una calle habanera que habla por sí misma:

Conde calculó que en aquellos cien metros de calle debía de haber más de sesenta personas inventando un modo cualquiera de arreglarse la vida o de verla pasar de la manera menos traumática posible. La sensación de degradación que flotaba en el aire alarmó al espíritu del ex policía, que percibió en la piel un temblor demasiado parecido al miedo: aquel ambiente era definitivamente explosivo, ajeno a la ciudad amable donde él había vivido por tantos años. Demasiadas gentes sin nada que hacer o perder. Demasiadas gentes sin sueños ni esperanzas. Demasiado fuego bajo una olla tapada, que más tarde o más temprano reventaría por las atmósferas de presión acumuladas (141). 


\section{Bibliografía}

Padura Fuentes, Leonardo, 1997, Máscaras, Barcelona, Tusquets

Padura Fuentes, Leonardo, 1998, Paisaje de otoño, Barcelona, Tusquets

Padura Fuentes, Leonardo, 2000, Pasado perfecto, Barcelona, Tusquets

Padura Fuentes, Leonardo, 2005, La neblina del ayer, Barcelona, Tusquets

Padura Fuentes, Leonardo, 2010, «Cuba y la literatura: vocación y posibilidad», conferencia, curso UIMP agosto 2010.

Wieser, Doris, 2005, «Leonardo Padura: Siempre me he visto como uno más de los autores cubanos », in http://www.ucm.es/info/especulo/numero29/padura.html. 